\title{
Educators' perception towards automation of curriculum design process for institution of higher learning in Malaysia
}

\begin{abstract}
Curriculum design is an important phase in curriculum development process. Curriculum design precedes its submission to national regulatory body for approval. Curriculum design process plays an important role in helping educators to produce curriculum that is incompliance with the program standards and guidelines set by national regulatory body. The traditional approach requires much cumbersome manual iteration, making the process longer and error-prone. It is believed that automating the design process by utilizing advanced IT/ICT technologies helps to increase effectiveness and efficiency. Hence, a preliminary study is conducted to determine the perception of needs relative to automation of curriculum design process and current obstacles or issues during the design process. Five experienced educators from both private and public Institutions of Higher Learning in Malaysia who are involved in curriculum design are interviewed. The design process may vary from one university to another, as well as from one faculty to another. The purpose of this study serves as a preliminary study. This preliminary study has been conducted based on the authors' prior work. This study creates an awareness of the extent of needs for design process automation supported by IT/ICT. These needs may be reflected in the planning of future research.
\end{abstract}

Keyword: Educators; Curriculum; Curriculum designer; Constrcution alignment 